\title{
Novel CTCF mutations in Chinese patients with ovarian endometriosis
}

\author{
JIUBAI GUO ${ }^{1}$, BIANNA CAO $^{1}, \mathrm{XIAOYUN} \mathrm{XU}^{1}$, FEI WU ${ }^{1}$ and BIN $\mathrm{ZHU}^{2}$ \\ ${ }^{1}$ Department of Gynecology, Jiangxi Provincial Maternal and Child Health Hospital, Nanchang, Jiangxi 330006; \\ ${ }^{2}$ Gongqing College of Nanchang University, Gongqingcheng, Jiangxi 332020, P.R. China
}

Received December 29, 2017; Accepted May 1, 2018

DOI: $10.3892 / \mathrm{mmr} .2018 .9049$

\begin{abstract}
Endometriosis is a common gynecological disease characterized by the outgrowth of the endometrium, however, the detailed molecular etiology remains largely uncharacterized. Recent studies have implicated that endometriosis is potentially a precancerous lesion, and that CCCTC-binding factor (CTCF) mutations may be involved in the pathogenesis of this disorder. However, the detailed CTCF mutation spectrum in Chinese patients with ovarian endometriosis remains largely unknown. In the present study, a cohort of 92 patients with ovarian endometriosis were analyzed for the presence of CTCF mutations by sequencing the entire coding regions. In addition, 67 healthy eutopic endometrial tissues and 46 healthy ovarian tissues from control samples (without endometriosis) were also analyzed. In total, two CTCF missense mutations, p.K206E (c.616A $>$ G) and p.H373L (c.1118A $>$ T), were identified in $2 / 92$ (2.2\%) endometriotic lesions. The patient with the p.K206E mutation was 26 years old and diagnosed with primary infertility, whereas the patient with the p.H373L mutation was 37 years old and concurrently diagnosed with uterine leiomyoma. The p.H373L mutation was previously identified in endometrial cancer samples with low frequency, while the p.K206E mutation was novel. In addition, no CTCF mutations were detected in the 67 healthy eutopic endometrial and 46 healthy ovarian tissue samples. In silico prediction and evolutionary conservation analysis suggested that these CTCF mutations may be pathogenic. In summary, the present study identified 2 potential pathogenic CTCF mutations in endometriotic lesions from 2/92 patients with ovarian endometriosis. These results, together with a prior exome-sequencing based study, suggest that CTCF mutations may be involved in the development of ovarian endometriosis.
\end{abstract}

Correspondence to: Dr Bin Zhu, Gongqing College of Nanchang University, 50 Nanhu Avenue, Gongqingcheng, Jiangxi 332020, P.R. China

E-mail: 490503416@qq.com

Key words: Chinese, CCCTC-binding factor, mutations, ovarian endometriosis

\section{Introduction}

Endometriosis is a common gynecological disease characterized by the growth of endometrial tissue outside of the uterine cavity $(1,2)$. It can be subdivided into three main subtypes according to the site of the growth, namely, ovarian endometriosis, pelvic endometriosis and deep infiltrating endometriosis $(3,4)$. The main clinical features of endometriosis include pelvic pain, dysmenorrhea and infertility, and this condition may affect up to $15 \%$ of women of reproductive age (5-7).

Despite extensive investigation, the detailed molecular etiology of endometriosis is still not fully understood $(8,9)$. It has been determined that genetic factors are involved in the development of endometriosis based on observations of the familial occurrence of this disorder, as the first-degree relatives of individuals with endometriosis exhibit a higher risk $(10,11)$. Alternatively, endometriosis has been proposed to be a precancerous lesion, since certain subtypes of ovarian and endometrial cancers have been implicated as being derived from this disease (12-14). Furthermore, somatic mutations in multiple oncogenes and tumor suppressor genes, including KRAS, protein phosphatase 2 scaffold subunit A alpha (PPP2R1A), phosphatidylinositol-4,5-bisphosphate 3-kinase catalytic subunit alpha (PIK3CA) and AT-rich interaction domain 1A (ARID1A), have been identified in certain subtypes of endometriosis via large-scale genomic analysis (15) and candidate gene strategy (16).

CTCF is an essential epigenetic regulator that affects chromatin structure organization to control gene transcription via facilitating or preventing promoter-enhancer interactions $(17,18)$. Previous studies have identified frequent CTCF mutations in diverse human cancer types, including endometrial cancer (19-21), and CTCF mutations have been shown to promote the progress of endometrial cancer (19). Although a previous exome-sequencing study identified CTCF somatic mutations in 16 ovarian endometriosis samples (22), due to the great heterogeneity of this disease, the detailed CTCF mutation spectrum of ovarian endometriosis samples remains largely undetermined $(23,24)$. Therefore, in the present study, a cohort of 92 ovarian endometriosis samples was collected in order to identify the somatic CTCF mutations of the endometriotic lesions. 


\section{Patients and methods}

Patients. The present study included 92 Chinese patients with ovarian endometriosis enrolled at the Jiangxi Provincial Maternal and Child Health Hospital from June 2013 to July 2014. Following assessment by two independent pathologists, paired endometriotic lesions and EDTA-anticoagulated blood samples were simultaneously collected from each patient. Samples of healthy eutopic endometrial tissues from 67 control patients without endometriosis, and of healthy ovarian tissues from 46 patients with ovarian cysts (without endometriosis) were also collected. This study was performed in accordance with the Declaration of Helsinki. The Institutional Review Board of the Jiangxi Provincial Maternal and Child Health Hospital approved the study. Informed consent was obtained from all participants prior to the study commencing.

Clinical data. The current age and the age at the time of menarche of each patient was recorded (Table I). The serum estrogen, progesterone, cancer antigen 125 (CA125), thyroid stimulating hormone (TSH), free triiodothyronine (FT3), free thyroxine (FT4), carcino embryonic antigen (CEA), $\alpha$-fetoprotein (AFP) and squamous cell carcinoma antigen (SCCA) levels were determined with a radioimmunoassay method, as previously described (25).

Mutational analysis of the CTCF gene. Total DNA was extracted from the endometriotic lesions and paired blood samples using the TIANamp Blood DNA kit (Tiangen Biotech Co., Ltd., Beijing, China). The DNA was quantified using a SmartSpec Plus spectrophotometer (Bio-Rad Laboratories, Inc., Hercules, CA, USA). The entire coding regions of the CTCF gene were PCR amplified with a series of primer pairs (Table II). Briefly, 50 ng total DNA was used for each PCR amplicon in a final volume of $30 \mu \mathrm{l}$ with rTaq DNA polymerase (Takara Biotechnology, Dalian, China). The PCR conditions were: One denaturation cycle $\left(94^{\circ} \mathrm{C}\right.$ for $\left.3 \mathrm{~min}\right), 35 \mathrm{PCR}$ cycles of denaturation, annealing and product extension $\left(94^{\circ} \mathrm{C}\right.$ for $30 \mathrm{sec} ; 50-60^{\circ} \mathrm{C}$ as specified in Table II for $30 \mathrm{sec} ; 72^{\circ} \mathrm{C}$ for $30 \mathrm{sec})$ and a final extension step $\left(72^{\circ} \mathrm{C}\right.$ for $\left.10 \mathrm{~min}\right)$. The PCR products were visualized on a $1.5 \%$ agarose gel stained with ethidium bromide and purified with a TIANgel Midi DNA Purification kit (Tiangen Biotechnology, Beijing, China). The purified PCR products were sequenced with an ABI Prism 3730 DNA sequencer (Applied Biosystems; Thermo Fisher Scientific, Inc., Waltham, MA, USA). The potential CTCF somatic mutations were verified by comparison with the paired blood samples. The identified mutations were searched in the HGMD (www.hgmd.cf.ac.uk/ac/index. php), dbSNP (www.ncbi.nlm.nih.gov/snp), ExAC (exac. broadinstitute.org) or 1000G (www.ncbi.nlm.nih.gov/variation/tools/1000genomes) databases.

Evolutionary conservation analysis. Evolutionary conservation analysis was used to evaluate the potential pathogenicity of the identified CTCF mutations. A total of 20 different vertebrate species sequences were retrieved from the GenBank database (www.ncbi.nlm.nih.gov/genbank), including Homo sapiens (NP_006556), Pan troglodytes (XP_009429318),
Mus musculus (NP_851839), Rattus norvegicus (NP_114012), Heterocephalus glaber (XP_021112509), Mesocricetus auratus (XP_012973364), Cricetulus griseus (XP_003508601), Bos taurus (NP_001069216), Bison bison (XP_010849335), Tursiops truncatus (XP_004317606), Canis lupus familiaris (XP_005620876), Sus scrofa (NP_001231589), Ovis aries (XP_012045353), Equus caballus (XP_001497859), Pteropus alecto (XP_015443188), Hipposideros armiger (XP_019511268), Pygoscelis adeliae (XP_009328626), Gallus gallus (NP_990663), Columba livia (XP_021157070) and Danio rerio (NP_001001844). Sequence alignment was performed with MEGA software (version 4.0) (26).

In silico analysis of the CTCF mutations. Two online bioinformatics programs were used to predict the pathogenic potential of the identified CTCF mutations, including MutationTaster (www.mutationtaster.org) (27) and PolyPhen-2 (genetics.bwh. harvard.edu/pph2) (28). These programs predict whether each mutation is likely to be to be benign or pathogenic, according to the probability score.

Statistical analysis. SPSS 17.0 statistical package (SPSS, Inc., Chicago, IL, USA) was used to calculate statistical significance. The Fisher's exact test was used to assess the potential association between nominal variables and CTCF mutation, whereas the Mann-Whitney method was used to analyze the potential association between continuous variables and CTCF mutations. $\mathrm{P}<0.05$ was considered to indicate a statistically significant difference and all P-values were two-tailed.

\section{Results}

CTCF mutation in ovarian endometriosis. The study consisted of 92 patients with ovarian endometriosis; the age range was 21-50 years, the age of menarche range was 10-18 years, and the serum estrogen, progesterone, CA125, TSH, FT3, FT4, CEA, AFP and SCCA levels are summarized in Table I. In total, 2 different somatic heterozygote CTCF mutations were identified in the endometriotic lesions in 2/92 (2.2\%) ovarian endometriosis tissue samples, including a p.K206E (c.616A>G) and a p.H373L (c.1118A>T) mutation. These mutations were not identified in the paired blood samples, indicating that they were somatic (Fig. 1). The p.K206E-mutated sample was from a 26-year-old woman who also experienced primary infertility, while the p.H373L-mutated individual was a 37-year-old who was also diagnosed with uterine leiomyoma. The p.H373L mutation was identified in 1/699 endometrial cancer samples in a previous study (29), while the p.K206E mutation was not previously reported either in the HGMD or dbSNP databases. In addition, somatic CTCF mutations were not detected in the remaining 90 ovarian endometriosis samples or in the 67 healthy control eutopic endometrial tissues and 46 healthy ovarian tissue samples from patients with ovarian cysts.

Association of CTCF mutations with clinical features. The potential associations between CTCF mutations and clinical features were analyzed. This analysis did not identify any associations between CTCF mutations and the clinical features considered (Table I). 
Table I. Association of CTCF mutation with clinical features in 92 patients with ovarian endometriosis.

\begin{tabular}{lccc}
\hline Feature & Wild type $(\mathrm{n}=90)$ & Mutant type $(\mathrm{n}=2)$ & P-value \\
\hline Age (years) & $33.46 \pm 6.62$ & $31.50 \pm 7.78$ & 0.35 \\
Age of menarche (years) & $13.23 \pm 1.23$ & $13.50 \pm 2.12$ & 0.81 \\
E2 $(\mathrm{pg} / \mathrm{ml})$ & $122.65 \pm 86.23$ & $75.61 \pm 53.25$ & 0.56 \\
P $(\mathrm{ng} / \mathrm{ml})$ & $1.48 \pm 3.21$ & $0.85 \pm 0.49$ & 0.86 \\
CA125 $(\mu / \mathrm{ml})$ & $112.38 \pm 198.23$ & $85.03 \pm 18.60$ & 0.62 \\
TSH $(\mathrm{mIU} / \mathrm{ml})$ & $2.34 \pm 1.12$ & $1.82 \pm 0.63$ & 0.20 \\
FT3 $(\mathrm{pg} / \mathrm{ml})$ & $2.95 \pm 0.26$ & $3.07 \pm 0.08$ & 0.65 \\
FT4 $(\mathrm{ng} / \mathrm{dl})$ & $1.27 \pm 0.08$ & $1.29 \pm 0.07$ & 0.49 \\
CEA $(\mathrm{ng} / \mathrm{ml})$ & $1.13 \pm 0.38$ & $0.92 \pm 0.16$ & 0.40 \\
AFP $(\mathrm{ng} / \mathrm{ml})$ & $2.89 \pm 1.82$ & $2.96 \pm 0.89$ & 0.18 \\
SCCA $(\mathrm{ng} / \mathrm{ml})$ & $1.43 \pm 1.08$ & $1.28 \pm 1.06$ & 0.46 \\
\hline
\end{tabular}

CTCF, CCCTC-binding factor; E2, estrogen; P, progesterone; CA125, cancer antigen 125; TSH, thyroid stimulating hormone; FT3, free triiodothyronine; FT4, free thyroxine; CEA, carcinoembryonic antigen; AFP, $\alpha$-fetoprotein; SCCA, squamous cell carcinoma antigen.

Table II. PCR primer sequences for the amplification of CTCF.

\begin{tabular}{|c|c|c|c|c|}
\hline Exon & Forward primer $\left(5^{\prime} \rightarrow 3^{\prime}\right)$ & Reverse primer $\left(5^{\prime} \rightarrow 3^{\prime}\right)$ & $\begin{array}{l}\text { Annealing temperature } \\
\qquad\left({ }^{\circ} \mathrm{C}\right)\end{array}$ & $\begin{array}{l}\text { Amplicon size } \\
\text { (bp) }\end{array}$ \\
\hline $3-1$ & TGCTTTAAATAACAATCT & TCTGAAGAAGGGTGGGGTC & 56 & 263 \\
\hline $3-2$ & AACAGCAGTGTACAGATG & СTTCTACTGAAGTGGTAGC & 52 & 235 \\
\hline $3-3$ & CAGCTTGTTCAAGTACCT & TGCCAACTAGGATCTTCC & 52 & 236 \\
\hline $3-4$ & GAGGTGGAGACACTAGAAC & CACTATGGATAAACTCGT & 58 & 285 \\
\hline 4 & ACTCTGCAGCAAGTAAGT & ACATTCTTATCCAGCAC & 50 & 224 \\
\hline 5 & TTCCTGTTACTCCATCCT & CTGCCTAAGAGAGATACCA & 55 & 199 \\
\hline 6 & CTCTTGTTACAGTCTGTG & GAGTGGAGAAGTCCTAC & 57 & 194 \\
\hline 7 & AATTACAGTATTTATTCA & CACTAGTTAATCTACTTA & 60 & 223 \\
\hline 8 & GGCTTTTTACTGTGCTT & ACACCAGACACCGAGAA & 55 & 230 \\
\hline 9 & CCCTATGCCGTTTCAGGA & AGGCAAAGTGAAGTTCTG & 50 & 225 \\
\hline 10 & AGTGGTGTGAAAGAGGAT & TCAAGGAACAAGTCACT & 56 & 191 \\
\hline 11 & TGCTTCCTGATTTCATGA & GAGATGAACAACTTACGC & 58 & 200 \\
\hline 12 & CTGTGCTCTTCTTTGCCAG & GCACAAGGCTCCGCCATC & 54 & 220 \\
\hline
\end{tabular}

CTCF, CCCTC-binding factor; bp, case pair.

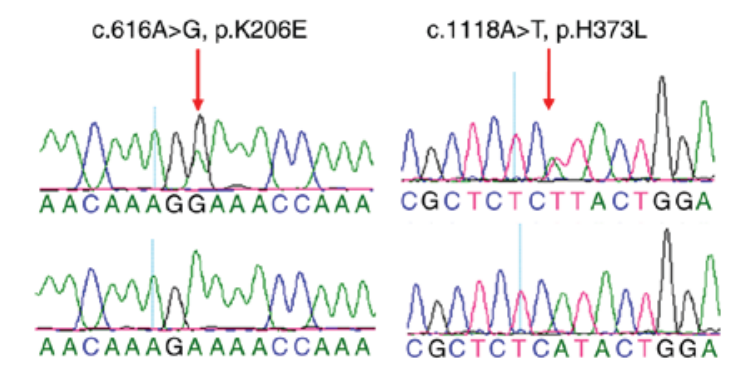

Figure 1. DNA sequencing electropherograms of the CTCF gene in the endometriotic lesions and paired blood samples. Arrows indicate the locations of mutations.

The causative potential of the CTCF mutations. The potential pathogenicity of the identified CTCF mutations was evaluated by MutationTaster and PolyPhen-2 programs. The p.K206E and p.H373L mutations scored 56 and 99 on MutationTaster, respectively, and were predicted to be 'disease causing' mutations. The Poly-Phen 2 program predicted that the p.K206E mutation was 'possibly damaging' and the p.H373L was 'probably damaging', with a score of 0.956 for p.K206E (sensitivity, 0.79; specificity, 0.95) and 0.997 for p.H373L (sensitivity, 0.41; specificity, 0.98), with mutations considered 'probably damaging' when the prediction score value was $>0.95$ (28). The two identified mutations were not reported in either the ExAC or $1000 \mathrm{G}$ databases.

Evolutionary conservation analysis of the CTCF mutations. The conservation trends of the CTCF amino acids were investigated based on sequence alignment with the human CTCF 


\begin{tabular}{|c|c|c|c|c|c|c|c|c|c|c|c|c|c|c|c|c|c|c|c|c|c|c|c|}
\hline \multicolumn{13}{|c|}{ c.616A>G, p.K206E } & \multicolumn{11}{|c|}{ c.1118A>T, p.H373L } \\
\hline Homo sapiens & A & $\mathrm{K}$ & K & $\mathrm{T}$ & $\mathrm{K}$ & $\mathrm{K}$ & $\mathrm{T}$ & $\mathrm{K}$ & $\mathrm{K}$ & $\mathrm{S}$ & $\mathrm{K}$ & Homo sapiens & $\mathrm{R}$ & $\mathrm{H}$ & I & R & s & $\mathrm{H}$ & $\mathrm{T}$ & G & $E$ & $\mathrm{R}$ & $\mathrm{P}$ \\
\hline OCT-15 & A & $\mathrm{K}$ & K & $\mathrm{T}$ & $\mathrm{K}$ & $E$ & $\mathrm{~T}$ & K & $\mathrm{K}$ & S & $\mathrm{K}$ & ОСТ-5 & $\mathrm{R}$ & $\mathrm{H}$ & 1 & R & s & L & $\mathrm{T}$ & G & $E$ & $\mathrm{R}$ & $\mathrm{P}$ \\
\hline Pan troglodytes & A & $\mathrm{K}$ & K & $\mathrm{T}$ & $\mathrm{K}$ & $\mathrm{K}$ & $\mathrm{T}$ & $\mathrm{K}$ & $\mathrm{K}$ & S & $\mathrm{K}$ & Pan troglodytes & $\mathrm{R}$ & $\mathrm{H}$ & 1 & R & s & $\mathrm{H}$ & $\mathrm{T}$ & G & E & $\mathrm{R}$ & $\mathrm{P}$ \\
\hline Mus musculus & A & $\mathrm{K}$ & K & $\mathrm{T}$ & $\mathrm{k}$ & K & $\mathrm{T}$ & K & $\mathrm{K}$ & s & $\mathrm{K}$ & Mus musculus & $\mathrm{R}$ & $\mathrm{H}$ & I & R & s & $\mathrm{H}$ & $\mathrm{T}$ & G & $\mathrm{E}$ & $\mathrm{R}$ & $\mathrm{P}$ \\
\hline Rattus norvegicus & A & $\mathrm{K}$ & K & $\mathrm{T}$ & $\mathrm{K}$ & $\mathrm{K}$ & $\mathrm{T}$ & K & $\mathrm{K}$ & S & $\mathrm{K}$ & Rattus norvegicus & $\mathrm{R}$ & $\mathrm{H}$ & 1 & R & s & $\mathrm{H}$ & $\mathrm{T}$ & G & $E$ & $\mathrm{R}$ & $\mathrm{P}$ \\
\hline Heterocephalus glaber & A & $\mathrm{K}$ & K & $\mathrm{T}$ & $\mathrm{K}$ & K & $\mathrm{T}$ & K & K & S & $\mathrm{K}$ & Heterocephalus glaber & $\mathrm{R}$ & $\mathrm{H}$ & I & $\mathrm{R}$ & s & $\mathrm{H}$ & $\mathrm{T}$ & G & $\mathrm{E}$ & $\mathrm{R}$ & $\mathrm{P}$ \\
\hline Mesocricetus auratus & A & $\mathrm{K}$ & $\mathrm{K}$ & $\mathrm{T}$ & $\mathrm{k}$ & $\mathrm{K}$ & $\mathrm{T}$ & $\mathrm{K}$ & $\mathrm{K}$ & $\mathrm{S}$ & $\mathrm{K}$ & Mesocricetus auratus & $\mathrm{R}$ & $\mathrm{H}$ & I & R & s & $\mathrm{H}$ & $\mathrm{T}$ & G & $\mathrm{E}$ & $\mathrm{R}$ & $\mathrm{P}$ \\
\hline Cricetulus griseus & A & $\mathrm{K}$ & K & $S$ & $\mathrm{~K}$ & $\mathrm{~K}$ & $\mathrm{~T}$ & K & $\mathrm{K}$ & S & $\mathrm{K}$ & Cricetulus griseus & $\mathrm{R}$ & $\mathrm{H}$ & I & R & s & $\mathrm{H}$ & s & G & $E$ & $\mathrm{R}$ & $\mathrm{P}$ \\
\hline Bos taurus & A & $\mathrm{K}$ & K & $\mathrm{T}$ & $\mathrm{k}$ & $\mathrm{K}$ & $\mathrm{T}$ & $\mathrm{K}$ & $\mathrm{K}$ & $\mathrm{S}$ & $\mathrm{K}$ & Bos taurus & $R$ & $\mathrm{H}$ & I & $\mathrm{R}$ & s & $\mathrm{H}$ & $\mathrm{T}$ & G & $\mathrm{E}$ & $R$ & $\mathrm{P}$ \\
\hline Bison bison & A & $\mathrm{K}$ & K & $\mathrm{T}$ & $\mathrm{K}$ & $\mathrm{K}$ & $\mathrm{T}$ & $\mathrm{K}$ & $\mathrm{K}$ & $\mathrm{S}$ & $\mathrm{K}$ & Bison bison & $\mathrm{R}$ & $\mathrm{H}$ & I & R & s & $\mathrm{H}$ & $\mathrm{T}$ & $\mathrm{G}$ & E & $\mathrm{R}$ & $\mathrm{P}$ \\
\hline Tursiops truncatus & A & $\mathrm{K}$ & $\mathrm{K}$ & $\mathrm{T}$ & $\mathrm{k}$ & $\mathrm{K}$ & $\mathrm{T}$ & $\mathrm{K}$ & $\mathrm{K}$ & S & $\mathrm{K}$ & Tursiops truncatus & $R$ & $\mathrm{H}$ & I & $\mathbf{R}$ & s & $\mathrm{H}$ & $\mathrm{T}$ & G & $E$ & $\mathrm{R}$ & $\mathrm{P}$ \\
\hline Canis lupus familiaris & A & $\mathrm{K}$ & K & $\mathrm{T}$ & $\mathrm{k}$ & K & $\mathrm{T}$ & K & $\mathrm{K}$ & $\mathrm{S}$ & $\mathrm{K}$ & Canis lupus familiaris & $\mathrm{R}$ & $\mathrm{H}$ & I & $\mathbf{R}$ & S & $\mathrm{H}$ & $\mathrm{T}$ & G & $\mathrm{E}$ & $\mathrm{R}$ & $\mathrm{P}$ \\
\hline Sus scrofa & A & $\mathrm{K}$ & K & $\mathrm{T}$ & $\mathrm{K}$ & $\mathrm{K}$ & $\mathrm{T}$ & $\mathrm{K}$ & $\mathrm{K}$ & $\mathrm{S}$ & $\mathrm{K}$ & Sus scrofa & $\mathrm{R}$ & $\mathrm{H}$ & I & $\mathrm{R}$ & s & $\mathrm{H}$ & $\mathrm{T}$ & $\mathrm{G}$ & $E$ & $\mathrm{R}$ & $\mathrm{P}$ \\
\hline Ovis aries & A & $\mathrm{K}$ & K & $\mathrm{T}$ & $\mathrm{k}$ & $\mathrm{K}$ & $\mathrm{T}$ & K & $\mathrm{K}$ & $\mathrm{S}$ & $\mathrm{K}$ & Ovis aries & $\mathrm{R}$ & $\mathrm{H}$ & 1 & R & s & $\mathrm{H}$ & $\mathrm{T}$ & G & $\mathrm{E}$ & $\mathrm{R}$ & $\mathrm{P}$ \\
\hline Equus caballus & A & $\mathrm{K}$ & K & $\mathrm{T}$ & $\mathrm{K}$ & $\mathrm{K}$ & $\mathrm{T}$ & $\mathrm{K}$ & $\mathrm{K}$ & $\mathrm{S}$ & $\mathrm{K}$ & Equus caballus & R & $\mathrm{H}$ & I & R & s & $\mathrm{H}$ & $\mathrm{T}$ & G & $E$ & $\mathrm{R}$ & $\mathrm{P}$ \\
\hline Pteropus alecto & A & $\mathrm{K}$ & K & $\mathrm{T}$ & $\mathrm{K}$ & K & $\mathrm{T}$ & K & $\mathrm{K}$ & S & $\mathrm{K}$ & Pteropus alecto & $R$ & $\mathrm{H}$ & 1 & $\mathrm{R}$ & s & $\mathrm{H}$ & $\mathrm{T}$ & G & $\mathrm{E}$ & $\mathrm{R}$ & $\mathrm{P}$ \\
\hline Hipposideros armiger & A & $\mathrm{K}$ & K & $\mathrm{T}$ & $\mathrm{K}$ & $\mathrm{K}$ & $\mathrm{T}$ & K & $\mathrm{K}$ & $\mathrm{S}$ & $\mathrm{K}$ & Hipposideros armiger & $R$ & $\mathrm{H}$ & 1 & R & $\mathrm{s}$ & $\mathrm{H}$ & $\mathrm{T}$ & G & $\mathrm{E}$ & $\mathrm{R}$ & $\mathrm{P}$ \\
\hline Pygoscelis adeliae & A & $\mathrm{K}$ & $\mathrm{K}$ & $\mathrm{T}$ & $\mathrm{K}$ & $\mathrm{K}$ & $\mathrm{N}$ & $\mathrm{K}$ & $\mathrm{K}$ & S & $\mathrm{K}$ & Pygoscelis adeliae & $\mathrm{R}$ & $\mathrm{H}$ & 1 & $\mathrm{R}$ & s & $\mathrm{H}$ & $\mathrm{T}$ & G & $E$ & $\mathrm{R}$ & $\mathrm{P}$ \\
\hline Gallus gallus & A & $\mathrm{K}$ & $\mathrm{K}$ & $\mathrm{T}$ & $\mathrm{K}$ & $\mathrm{K}$ & $\mathrm{N}$ & $\mathrm{K}$ & $\mathrm{K}$ & s & $\mathrm{K}$ & Gallus gallus & $\mathrm{R}$ & $\mathrm{H}$ & 1 & R & s & $\mathrm{H}$ & $\mathrm{T}$ & G & $E$ & $\mathrm{R}$ & $P$ \\
\hline Columba livia & A & $\mathrm{K}$ & K & I & $\mathrm{K}$ & $\mathrm{K}$ & N & K & $\mathrm{K}$ & S & $\mathrm{K}$ & Columba livia & $R$ & $\mathrm{H}$ & 1 & R & s & $\mathrm{H}$ & $\mathrm{T}$ & G & E & $\mathrm{R}$ & $\mathrm{P}$ \\
\hline Danio rerio & V & $\mathrm{K}$ & $\mathrm{K}$ & V & & $\mathrm{K}$ & $\mathrm{T}$ & $\mathrm{K}$ & K & $\mathrm{S}$ & $\mathrm{K}$ & Danio rerio & $\mathrm{R}$ & $\mathrm{H}$ & I & $\mathrm{R}$ & s] & $\mathrm{H}$ & $\mathrm{T}$ & $\mathrm{G}$ & $E$ & $\mathrm{R}$ & \\
\hline
\end{tabular}

Figure 2. Evolutionary conservation analysis of the sites of the identified CTCF mutations in 20 different vertebrate species. Both of the identified mutations were located in highly evolutionarily conserved amino acid residues.

protein sequence. The alignment results showed that the two potentially pathogenic mutations (p.K206E and p.H373L) were at highly conserved sites in the 20 vertebrate species, from Homo sapiens to Danio rerio (Fig. 2).

\section{Discussion}

As a critical chromatin-organizing factor, CTCF serves an important role in chromatin insulation, enhancer blocking and transcriptional regulation $(17,18,30,31)$. CTCF mutations are frequently identified in endometrial cancer $(20,21,29)$, while they are less common in several other cancer types, including liver (32) and breast (33) cancer. As endometriosis, a potentially premalignant condition, shares some genetic features with CTCF-mutated endometrial cancer, including frequent KRAS and PIK3CA mutations $(20,34,35)$, the present study hypothesized that there may also be CTCF mutations in endometriotic lesions.

In the present study, 2 heterozygous somatic mutations in CTCF, p.K206E (c.616A>G) and p.H373L (c.1118A>T), were identified in 2/92 ovarian endometriosis samples. The association of CTCF mutations with endometriosis remains largely uncharacterized, with the exception of two previous large-scale genomic analyses profiling global somatic mutations in endometriosis, including a study of 16 Chinese patients with ovarian endometriosis (22), and of 24 Euro-American and Japanese patients with deeply infiltrating endometriosis (15). The mutation frequency of CTCF in the samples of the present study was notably different from these two previous studies; the previous exome-based sequencing effort identified a CTCF mutation frequency of $25 \%(4 / 16 ; \mathrm{P}=0.004)$ in Chinese patients with ovarian endometriosis (22). It can be hypothesized that the high sensitivity for the detection of mutations using the exome sequencing technique may be the main reason for the differential mutation frequency between the present study and the previous study (36). The identified CTCF mutations in the previous study (22) were not subject to Sanger sequencing verification, which has a detection threshold of 6.6-20\% mutant alleles (37-39). The other genomic analysis of 24 patients with deeply infiltrating endometriosis failed to identify any CTCF mutations (15); one possible explanation is that CTCF mutations may be specific to ovarian endometriosis. However, this hypothesis should be treated with caution due to the relatively small sample size of the previous study (15). Additionally, CTCF mutations were not identified in the 67 healthy eutopic endometrial tissues samples and 46 health ovarian tissue samples from patients with ovarian cysts, implying that CTCF mutations may participate in the development of ovarian endometriosis.

The present study failed to identify any association between CTCF mutations and the clinical characteristics of the sample cohort; however, this conclusion should also be treated with caution, as the sample size of patients with CTCF mutation was too small $(n=2)$. To overcome this potential statistical bias, the association should be further analyzed with a larger sample size in a future study.

The in silico prediction results indicated that the two CTCF mutations were 'probably damaging', while the evolutionary conservation analysis results showed the two mutated amino acids were evolutionarily highly conserved across 20 vertebrate species, from Homo sapiens to Danio rerio. Furthermore, the p.H373L mutation identified in the present study was previously detected in 1 of 699 patients with endometrial cancer (29). These results imply that the CTCF mutations identified in the patients with ovarian endometriosis may be pathogenic. Combined with the high frequency of 
CTCF mutations in ovarian endometriosis in the previous study (22), it can be hypothesized that CTCF mutations may contribute to the pathogenesis of ovarian endometriosis.

In conclusion, the present study identified two CTCF somatic mutations in the endometriotic lesions of Chinese patients with ovarian endometriosis. In silico prediction and evolutionary conservation analysis implied that these mutations may be pathogenic. The findings of the present study, together with previous studies, suggest that CTCF mutations may contribute to the development of ovarian endometriosis.

\section{Acknowledgements}

Not applicable.

\section{Funding}

The present study was supported by a grant from the Natural Science Foundation of Jiangxi Province (grant no. 20151BAB205012).

\section{Availability of data and materials}

All data generated or analyzed during this study are included in this published article.

\section{Authors' contributions}

JG performed the experiment. BC and XX performed data analysis. FW collected the sample and clinical data. BZ designed the study and prepared the manuscript.

\section{Ethics approval and consent to participate}

The Institutional Review Board of the Jiangxi Provincial Maternal and Child Health Hospital approved the study. Informed consent was obtained from all participants prior to the study commencing.

\section{Consent for publication}

Informed consent was obtained from all participants prior to the study commencing.

\section{Competing interests}

The authors declare that they have no competing interests.

\section{References}

1. Bedaiwy MA, Allaire C, Yong P and Alfaraj S: Medical management of endometriosis in patients with chronic pelvic pain. Semin Reprod Med 35: 38-53, 2017.

2. Cakmak H, Seval-Celik Y, Arlier S, Guzeloglu-Kayisli O, Schatz F, Arici A and Kayisli UA: p38 Mitogen-activated protein kinase is involved in the pathogenesis of endometriosis by modulating inflammation, but not cell survival. Reprod Sci 25: 587-597, 2018 .

3. Exacoustos C, Zupi E and Piccione E: Ultrasound Imaging for ovarian and deep infiltrating endometriosis. Semin Reprod Med 35: 5-24, 2017

4. Gordts S, Koninckx P and Brosens I: Pathogenesis of deep endometriosis. Fertil Steril 108: 872-885.e1, 2017.
5. Tanbo T and Fedorcsak P: Endometriosis-associated infertility: Aspects of pathophysiological mechanisms and treatment options. Acta Obstet Gynecol Scand 96: 659-667, 2017.

6. Chui MH, Wang TL and Shih IM: Endometriosis: Benign, malignant, or something in between? Oncotarget 8: 78263-78264, 2017.

7. Kohl Schwartz AS, Wölfler MM, Mitter V, Rauchfuss M, Haeberlin F, Eberhard M, von Orelli S, Imthurn B, Imesch P, Fink D and Leeners B: Endometriosis, especially mild disease: A risk factor for miscarriages. Fertil Steril 108: 806-814.e2, 2017.

8. Uimari O, Rahmioglu N, Nyholt DR, Vincent K, Missmer SA, Becker C, Morris AP, Montgomery GW and Zondervan KT: Genome-wide genetic analyses highlight mitogen-activated protein kinase (MAPK) signaling in the pathogenesis of endometriosis. Hum Reprod 32: 780-793, 2017.

9. Burghaus S, Fasching PA, Häberle L, Rübner M, Büchner K, Blum S, Engel A, Ekici AB, Hartmann A, Hein A, et al: Genetic risk factors for ovarian cancer and their role for endometriosis risk. Gynecol Oncol 145: 142-147, 2017.

10. Matalliotakis IM, Arici A, Cakmak H, Goumenou AG, Koumantakis G and Mahutte NG: Familial aggregation of endometriosis in the Yale series. Arch Gynecol Obstet 278: 507-511, 2008.

11. McLeod BS and Retzloff MG: Epidemiology of endometriosis: An assessment of risk factors. Clin Obstet Gynecol 53: 389-396, 2010.

12. Wiegand KC, Shah SP, Al-Agha OM, Zhao Y, Tse K, Zeng T, Senz J, McConechy MK, Anglesio MS, Kalloger SE, et al: ARID1A mutations in endometriosis-associated ovarian carcinomas. N Engl J Med 363: 1532-1543, 2010.

13. Wang Y, Mang M, Wang Y, Wang L, Klein R, Kong B and Zheng W: Tubal origin of ovarian endometriosis and clear cell and endometrioid carcinoma. Am J Cancer Res 5: 869-879, 2015.

14. Cochrane DR, Tessier-Cloutier B, Lawrence KM, Nazeran T, Karnezis AN, Salamanca C, Cheng AS, McAlpine JN, Hoang LN, Gilks CB and Huntsman DG: Clear cell and endometrioid carcinomas: Are their differences attributable to distinct cells of origin? J Pathol 243: 26-36, 2017.

15. Anglesio MS, Papadopoulos N, Ayhan A, Nazeran TM, Noë M, Horlings HM, Lum A, Jones S, Senz J, Seckin T, et al: Cancer-associated mutations in endometriosis without cancer. N Engl J Med 376: 1835-1848, 2017.

16. Vestergaard AL, Thorup K, Knudsen UB, Munk T, Rosbach H, Poulsen JB, Guldberg P and Martensen PM: Oncogenic events associated with endometrial and ovarian cancers are rare in endometriosis. Mol Hum Reprod 17: 758-761, 2011.

17. Hansen AS, Pustova I, Cattoglio C, Tjian R and Darzacq X: CTCF and cohesin regulate chromatin loop stability with distinct dynamics. Elife 6: pii: e25776, 2017.

18. Pérez-García A, Marina-Zárate E, Álvarez-Prado ÁF, Ligos JM, Galjart N and Ramiro AR: CTCF orchestrates the germinal centre transcriptional program and prevents premature plasma cell differentiation. Nat Commun 8: 16067, 2017.

19. Marshall AD, Bailey CG, Champ K, Vellozzi M, O'Young P Metierre C, Feng Y, Thoeng A, Richards AM, Schmitz U, et al: CTCF genetic alterations in endometrial carcinoma are pro-tumorigenic. Oncogene 36: 4100-4110, 2017.

20. Cancer Genome Atlas Research Network; Kandoth C, Schultz N, Cherniack AD, Akbani R, Liu Y, Shen H, Robertson AG, Pashtan I, Shen R, et al: Integrated genomic characterization of endometrial carcinoma. Nature 497: 67-73, 2013.

21. Walker CJ, Miranda MA, O'Hern MJ, McElroy JP, Coombes KR, Bundschuh R, Cohn DE, Mutch DG and Goodfellow PJ: Patterns of CTCF and ZFHX3 mutation and associated outcomes in endometrial cancer. J Natl Cancer Inst 107: pii: djv249, 2015.

22. Li X, Zhang Y, Zhao L, Wang L, Wu Z, Mei Q, Nie J, Li X, Li Y, Fu X, et al: Whole-exome sequencing of endometriosis identifies frequent alterations in genes involved in cell adhesion and chromatin-remodeling complexes. Hum Mol Genet 23: 6008-6021, 2014

23. Zondervan KT, Rahmioglu N, Morris AP, Nyholt DR, Montgomery GW, Becker CM and Missmer SA: Beyond endometriosis Genome-wide association study: From genomics to phenomics to the patient. Semin Reprod Med 34: 242-254, 2016.

24. Montgomery GW and Giudice LC: New lessons about Endometriosis-somatic mutations and disease heterogeneity. $\mathrm{N}$ Engl J Med 376: 1881-1882, 2017.

25. Wu J, Zou Y, Luo Y, Guo JB, Liu FY, Zhou JY, Zhang ZY, Wan L and Huang OP: Prevalence and clinical significance of mediator complex subunit 12 mutations in 362 Han Chinese samples with uterine leiomyoma. Oncol Lett 14: 47-54, 2017. 
26. Tamura K, Dudley J, Nei M and Kumar S: MEGA4: Molecular evolutionary genetics analysis (MEGA) software version 4.0. Mol Biol Evol 24: 1596-1599, 2007.

27. Schwarz JM, Cooper DN, Schuelke M and Seelow D: MutationTaster2: Mutation prediction for the deep-sequencing age. Nat Methods 11: 361-362, 2014.

28. Adzhubei IA, Schmidt S, Peshkin L, Ramensky VE, Gerasimova A, Bork P, Kondrashov AS and Sunyaev SR: A method and server for predicting damaging missense mutations. Nat Methods 7: 248-249, 2010.

29. Zighelboim I, Mutch DG, Knapp A, Ding L, Xie M, Cohn DE and Goodfellow PJ: High frequency strand slippage mutations in CTCF in MSI-positive endometrial cancers. Hum Mutat 35: 63-65, 2014.

30. Ohlsson R, Lobanenkov V and Klenova E: Does CTCF mediate between nuclear organization and gene expression? Bioessays 32: 37-50, 2010.

31. Bushey AM, Dorman ER and Corces VG: Chromatin insulators: Regulatory mechanisms and epigenetic inheritance. Mol Cell 32: $1-9,2008$

32. Fujimoto A, Furuta M, Totoki Y, Tsunoda T, Kato M, Shiraishi Y, Tanaka H, Taniguchi $\mathrm{H}$, Kawakami Y, Ueno M, et al: Whole-genome mutational landscape and characterization of noncoding and structural mutations in liver cancer. Nat Genet 48 : 500-509, 2016.

33. Aulmann S, Bläker H, Penzel R, Rieker RJ, Otto HF and Sinn HP: CTCF gene mutations in invasive ductal breast cancer. Breast Cancer Res Treat 80: 347-352, 2003.
34. Kuhn E, Wu RC, Guan B, Wu G, Zhang J, Wang Y, Song L, Yuan X, Wei L, Roden RB, et al: Identification of molecular pathway aberrations in uterine serous carcinoma by genome-wide analyses. J Natl Cancer Inst 104: 1503-1513, 2012.

35. Le Gallo M, O'Hara AJ, Rudd ML, Urick ME, Hansen NF, O'Neil NJ, Price JC, Zhang S, England BM, Godwin AK, et al: Exome sequencing of serous endometrial tumors identifies recurrent somatic mutations in chromatin-remodeling and ubiquitin ligase complex genes. Nat Genet 44: 1310-1315, 2012.

36. Xuan J, Yu Y, Qing T, Guo L and Shi L: Next-generation sequencing in the clinic: Promises and challenges. Cancer Lett 340: 284-295, 2013

37. Yao YG, Ogasawara Y, Kajigaya S, Molldrem JJ, Falcão RP, Pintão MC, McCoy JP Jr, Rizzatti EG and Young NS: Mitochondrial DNA sequence variation in single cells from leukemia patients. Blood 109: 756-762, 2007.

38. Tsiatis AC, Norris-Kirby A, Rich RG, Hafez MJ, Gocke CD, Eshleman JR and Murphy KM: Comparison of Sanger sequencing, pyrosequencing, and melting curve analysis for the detection of KRAS mutations: Diagnostic and clinical implications. J Mol Diagn 12: 425-432, 2010.

39. Monzon FA, Ogino S, Hammond ME, Halling KC, Bloom KJ and Nikiforova MN: The role of KRAS mutation testing in the management of patients with metastatic colorectal cancer. Arch Pathol Lab Med 133: 1600-1606, 2009. 